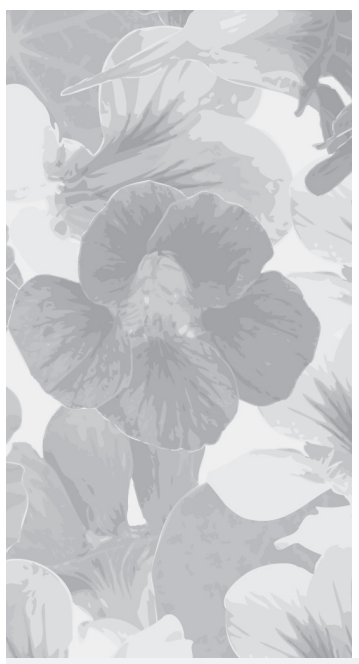

\title{
Częstość występowania trądziku późnego oraz jego wpływ na jakość życia młodych kobiet
}

\author{
Frequency of post-adolescent acne and its impact on the quality \\ of life of young women
}

Paulina Szczurek ${ }^{1}$, Grażyna Kamińska-Winciorek², Radosław Śpiewak ${ }^{1}$

${ }^{1}$ Zakład Dermatologii Doświadczalnej i Kosmetologii, Wydział Farmaceutyczny, Uniwersytet Jagielloński Collegium Medicum, Kraków

${ }^{2}$ Ośrodek Wczesnej Diagnostyki i Leczenia Nowotworów, Katowice

Estetol Med Kosmetol 2012; 2(2): 58-62

DOI: http://dx.doi.org/10.14320/EMK.2012.012

\section{Streszczenie}

Trądzik późny jest przewlekłą chorobą zapalną jednostki tojowo-włosowej, która dotyczy najczęściej mtodych kobiet w wieku około 25 lat. Cel: Ocena częstości występowania trądziku późnego oraz jego wpływu na jakość życia młodych dorosłych Polek. Materiał i metody: Dobrowolne anonimowe badanie ankietowe 128 studentek Wydziatu Farmaceutycznego Uniwersytetu Jagiellońskiego w wieku 21-35 lat. Wyniki: Spośród 128 ankietowanych kobiet, 95 przynajmniej raz w życiu miało problemy trądzikowe (chorobowość życiowa 74\%; 95\% Cl=67-82\%). Obecność zmian trądzikowych w momencie badania zdeklarowało 71 kobiet (chorobowość punktowa 55\%; 95\% Cl=47-64\%). Wiek pojawienia się pierwszych wykwitów trądzikowych mieścit się w zakresie 10-25 lat (mediana: 14 r.ż.). Do najczęściej wymienianych zmian należały zaskórniki otwarte (71\%) i zamknięte (46\%), a rzadziej krostki (42\%) i grudki (23\%). U większości respondentek wykwity trądzikowe lokalizowały się głównie na twarzy (67\%), w tym najczęściej na brodzie (46\%). Zmiany trądzikowe były postrzegane jako duży lub bardzo duży problem przez $40 \%$ osób z trądzikiem. Jednak $95 \%$ respondentek jednocześnie zadeklarowało że obecność trądziku nie powoduje problemów w kontaktach z najbliższą rodziną. Zmiany trądzikowe w bardzo niskim stopniu ograniczały również wyjścia z domu, a u żadnej respondentki stan skóry nie ograniczał uprawiania sportu, robienia zakupów, wyjść do kina czy na uczelnię. Wnioski: Trądzik późny dotyczy ponad połowy młodych dorosłych Polek i zazwyczaj jest kontynuacją trądziku młodzieńczego. Choroba ta obniża poczucie własnej atrakcyjności u dotkniętych nią kobiet i wpływa na ich codzienne zachowania, jednak w większości przypadków nie powoduje znacznego obniżenia jakości życia i nie stanowi istotnej przeszkody w codziennym funkcjonowaniu oraz kontaktach międzyludzkich.

Stowa kluczowe: trądzik późny, trądzik dorosłych, trądzik kobiet, kobiety, jakość życia

\begin{abstract}
Post-adolescent acne (adult female acne) is a chronic disorder of the pilosebaceous unit that typically affects young women around 25 years of age. Objective: To evaluate the prevalence of post-adolescent acne and its impact on the quality of life among young Polish women. Material and methods: An anonymous questionnaire survey of 128 female students of the Faculty of Pharmacy, Jagiellonian University, Krakow, Poland. Results: Of the 128 study participants, 95 had experienced acne problems at least once in their lives (lifetime prevalence $74 \% ; 95 \% \mathrm{Cl}=67-82 \%$ ). The presence of acne lesions at the time of responding to the questionnaire was reported by 71 respondents (point prevalence $55 \% ; 95 \% \mathrm{Cl}=47-64 \%$ ). The age at first appearance of the lesions ranged from $10-25$ years (median 14 years). Among the most frequently reported acne lesions were open comedones ( $71 \%$ ), closed comedones (46\%), and less frequently, pustules $(42 \%)$ and papules $(23 \%)$. In the majority of the respondents $(67 \%)$ the efflorescences were located mainly on the face, predominantly $(46 \%)$ in the mental area. Acne lesions and associated symptoms were considered as a big or very big problem by $40 \%$ of respondents with acne. However, $95 \%$ of respondents declared that the presence of acne does not impede relations within their families. Also, the skin conditions affected the outing activities of hardly any of the respondents, and it interfered with the sporting activities, shopping, going to the cinema or attending university in none of them. Conclusions: Post-adolescent acne affects more than a half of adult Polish women and typically is a continuation of adolescent acne vulgaris. This disease decreases the level of selfattractiveness of the affected women and influences their daily routines; however, in the majority of cases it does not cause a relevant decrease in the quality of life or pose a considerable obstacle to everyday functioning and interpersonal relations.
\end{abstract}

Keywords: post-adolescent acne, adult acne, female acne, women, quality of life

Copyright @ 2012 the Authors (text) and Radosław Śpiewak (layout \& journal compilation). All rights reserved.

Trądzik późny jest przewlekłą chorobą zapalną jednostki łojowo-włosowej, występującą najczęściej u młodych kobiet. Patomechanizm powstawania wykwitów w postaci późnej, podobnie jak w trądziku zwykłym, uwarunkowany jest nadmiernym wydzielaniem sebum przez gruczoły łojowe, nadmiernym rogowaceniem i zaczopowaniem ujść gruczołów łojowych oraz nadmierną proliferacją beztlenowych bakterii gram-dodatnich Propionibacterium acnes w obrębie gru- czołu łojowego, co prowokuje odczyn zapalny. Jednak klinicznie trądzik późny różni się od trądziku młodzieńczego, stąd potrzeba stosowania innych metod terapeutycznych. Wyróżnić można dwie odmiany trądziku późnego: Postać zapalna trądziku późnego charakteryzuje się występowaniem w dolnej części twarzy licznych grudek, krostek oraz zapalnych guzków ustępujących z pozostawieniem blizn, nie zawsze obserwuje się tu nasilony łojotok. W postaci retencyj- 
nej trądziku późnego typowe jest występowanie licznych zaskórników i mikrotorbieli, a łojotok zawsze jest znaczny [1]. Ze względu na historię naturalną choroby, można ją ponadto podzielić na 3 podtypy: ,przetrwały trądzik późny" stanowiący kontynuację trądziku młodzieńczego od wieku dojrzewania do dorosłego, ,pierwotny trądzik późny", którego pierwsze objawy pojawiają się po 25 roku życia, oraz ,nawrotowy trądzik późny" u osób, u których trądzik młodzieńczy ustąpił na kilka lat, a potem powrócił w życiu dorosłym [2]. Trądzik późny lokalizuje się głównie na twarzy, w szczególności w okolicach podbródka, żuchwy oraz wokół ust. Czasami zajęte są także ramiona i klatka piersiowa oraz szyja. Nasilenie choroby jest zwykle lekkie lub umiarkowane, rzadko występują postaci ciężkie z licznymi wykwitami. Stosunkowo dużo wiadomo na temat niekorzystnego wpływy trądziku młodzieńczego na jakość życia, jak dotąd nie przeprowadzono natomiast badań nad częstością występowania trądziku późnego w populacji dorosłych Polek oraz jego wpływem na jakość życia.

\section{Cel}

Celem badania była ocena częstości występowania trądziku późnego w grupie młodych dorosłych Polek oraz wpływu tej choroby na ich jakość życia.

\section{Materiat i metody}

Do dobrowolnego, anonimowego badania w marcu i kwietniu 2012 roku zaproszono 145 studentek Wydziału Farmaceutycznego Uniwersytetu Jagiellońskiego w Krakowie. Dane na temat występowania trądziku późnego i jego wpływu na życie studentów zebrano na podstawie autorskiej ankiety składającej się z 24 pytań. W badaniu pod uwagę wzięto 128 kompletnie wypełnionych ankiet. Po zakodowaniu wyników do arkusza kalkulacyjnego, dane poddano analizie statystycznej, polegającej na wyliczeniu odsetka odpowiedzi twierdzących na poszczególne pytania wraz z 95\% przedziałami ufności (95\%CI). Oryginalne ankiety przechowywane są w Zakładzie Dermatologii Doświadczalnej i Kosmetologii UJ w Krakowie.

\section{Wyniki}

Charakterystyka badanej grupy: Badaną grupę stanowiły słuchaczki studiów magisterskich na kierunkach: kosmetologia $(n=59,46 \%)$, farmacja $(n=38,30 \%)$ oraz analityka medyczna $(n=31,24 \%)$. Respondentki pochodziły w większości z województwa małopolskiego (52\%), a w dalszej kolejności z województwa śląskiego (12\%), podkarpackiego (11\%), świętokrzyskiego (10\%), opolskiego (5\%), lubelskiego (4\%), a ponadto łódzkiego, dolnośląskiego, zachodniopomorskiego oraz mazowieckiego (w każdym przypadku poniżej $2 \%$ ). Wiek respon- dentek wynosił od 21 do 35 lat (mediana 23 lata).

Ocena stanu skóry, czas trwania, typ, lokalizacja zmian trądzikowych: Spośród 128 badanych, 82 kobiety (64\%; 95\% CI $=56-72 \%)$ deklarowały, że mają cerę mieszaną, $26(20 \% ; 95 \% \mathrm{CI}=13-27 \%)$ oceniło swoją cerę jako suchą, $11(9 \% ; 95 \% \mathrm{CI}=4-13 \%)$ jako cerę tłustą, a zaledwie $9(7 \% ; 95 \% \mathrm{CI}=3-12 \%)$ ankietowanych uważało, że ma cerę normalną. Wystąpienie przynajmniej raz w życiu problemów trądzikowych zgłosiło 95 uczestniczek badania (chorobowość życiowa 74\%; 95\% $\mathrm{CI}=67-82 \%$ ), natomiast obecność zmian trądzikowych w momencie wypełniania ankiety zadeklarowało 71 kobiet (chorobowość punktowa 55\%; 95\%CI=47-64\%). Spośród 95 respondentek, które doświadczyły trądziku, wiek wystąpienia pierwszych zmian było w stanie podać 60 osób - mieścił się on w zakresie od 10 do 25 roku życia (dolny kwartyl 13 r.ż., mediana 14 r.ż., górny kwartyl 16 r.ż.). Wśród badanych mających problemy trądzikowe, większość zgłaszała obecność zaskórników, a w dalszej kolejności krostek i grudek (tabela 1). Wykwity te zlokalizowane były głównie na twarzy (tabela 2).

Czynniki dziedziczne i hormonalne: Spośród respondentek, które doświadczyły trądziku kiedykolwiek w życiu $(\mathrm{N}=95)$, zaledwie $16(17 \%$; 95\%CI=9-24\%) utrzymywało, że nie było przypadków trądziku w ich najbliższej rodzinie, natomiast 41 respondentek (43\%; 95\% $\mathrm{CI}=33-53 \%$ ) zgłosiło występowanie problemów trądzikowych u rodzeństwa, a $24(25 \%$; 95\% CI=17-34\%) u rodziców (w tym u ojca 14\%, u matki 13\%). 23 respondentki (24\%) nie potrafiły odpowiedzieć na pytanie o trądzik w najbliższej rodzinie. Zdecydowana większość respondentek (84 osoby, 88\%; 95\%CI=82-95\%) oceniła swoje miesiączki jako regularne, a deklarowana długość cyklu wynosiła od 21 do 36 dni (dolny kwartyl 28 , mediana 28, górny kwartyl 30). Jednocześnie znacząca większość badanych (80 osób, 84\%; 95\%CI=7792\%) zgłaszała nasilenie zmian trądzikowych przed miesiączką.

Dolegliwości towarzyszące oraz wpływ trądziku na jakość życia: Wśród dolegliwości subiektywnych związanych z trądzikiem zgłaszanych przez respondentów dominowało uczucie ściągania skóry (35osób, 37\%; $95 \% \mathrm{CI}=27-47 \%$ ), świąd (33 osoby, 35\%; 95\% CI=2544\%), ból (21 osób, 22\%; 95\%CI=14-30\%), uczucie pieczenia lub palenia skóry ( 9 osób, 10\%; 95\%CI=4-15\%) i uczucie szczypania ( 8 osób, $8 \%$; 95\%CI=3-14\%). Obecność zmian trądzikowych oraz związanych z nimi dolegliwości stanowiła duży lub bardzo duży problem dla 38 osób $(40 \%$; 95\% CI=30-50\%), z czego 25 osób (26\%; $95 \% \mathrm{CI}=17-35 \%)$ podało, że trądzik znacząco utrudnia ich codzienne funkcjonowanie, a 22 osoby $(23 \%$; $95 \% \mathrm{CI}=15-32 \%$ ) wyraziły przekonanie, że trądzik znacząco utrudnia ich kontakty z osobami płci przeciwnej. W przekonaniu 17 respondentek $(18 \%$; 95\% CI $=10-26 \%)$ 
trądzik powodował obniżenie ich poczucia własnej atrakcyjności, u 7 osób (7\%; 95\%CI=2-13\%) trądzik powodował uczucie skrępowania. Wśród dalszych skutków obecności zmian trądzikowych respondentki wymieniały poczucie niższej wartości, nieśmiałość, brak pewności siebie, depresję, drażliwość (w każdym przypadku po $6 \%$ badanych; $95 \% \mathrm{CI}=1-11 \%$ ), poczucie bycia nieszczęśliwą, złość, zawstydzenie, zażenowanie (po 5\% badanych; 95\%CI=1-10\%), poczucie odrzucenia, nerwowość (po 4\% badanych; 95\%CI=0-8\%), agresję i zachowania samookaleczające (po 2\% badanych; 95\%CI=0-5\%). Obecność zmian trądzikowych w znacznej mierze wpływała także na zachowania kobiet w sytuacjach codziennych (tabela 3 ).

Tabela 1. Rodzaj wykwitów trądzikowych zgłaszanych przez uczestniczki badania $(\mathrm{N}=95)$

\begin{tabular}{l|c|c}
\multicolumn{1}{c|}{ Wykwity } & $\mathbf{n}$ & $\mathbf{\% ~ ( 9 5 \% C I ) ~}$ \\
\hline Zaskórniki otwarte & 71 & $75(66-84)$ \\
\hline Zaskórniki zamknięte & 46 & $48(38-59)$ \\
\hline Krostki & 42 & $44(34-54)$ \\
\hline Grudki & 23 & $24(16-33)$ \\
\hline Blizny & 16 & $17(9-24)$ \\
\hline Torbiele & 7 & $7(2-13)$
\end{tabular}

$\mathrm{n}$ - liczba odpowiedzi pozytywnych

Tabela 2. Lokalizacja zmian trądzikowych podawana przez uczestniczki badania $(\mathrm{N}=95)$

\begin{tabular}{|c|c|c|}
\hline Lokalizacja & $\mathbf{n}$ & $\%(95 \% \mathrm{Cl})$ \\
\hline Twarz, w tym: & 64 & $67(58-77)$ \\
\hline Broda & 46 & $48(38-59)$ \\
\hline Czoło & 37 & $39(29-49)$ \\
\hline Nos & 36 & $38(28-48)$ \\
\hline Policzki & 25 & $26(18-35)$ \\
\hline Żuchwa & 21 & $22(14-30)$ \\
\hline Plecy & 28 & $30(20-39)$ \\
\hline Klatka piersiowa & 15 & $16(9-23)$ \\
\hline Ramiona & 12 & $13(6-19)$ \\
\hline Szyja & 1 & $1(0-3)$ \\
\hline
\end{tabular}

Dla 90 respondentek $(95 \%$; 95\%CI=90-99\%) obecność trądziku nie powodowała problemów w kontaktach $\mathrm{z}$ najbliższą rodziną. Zmiany trądzikowe w bardzo niskim stopniu ograniczały również wyjścia z domu - tylko 2 osoby $(2 \%$; $95 \% \mathrm{CI}=0-5 \%)$ podały, że trądzik ogranicza ich wyjścia na plażę, a pojedyncze osoby trądzik odwodził od wyjścia na spacer i na dyskotekę (po $1 \%$ badanych; $95 \% \mathrm{CI}=0-3 \%$ ). U żadnej respondentki stan skóry nie ograniczał uprawiania sportu, robienia zakupów, wyjść do kina czy na uczelnię.

\section{Dyskusja}

Trądzik jest jedną z najczęstszych chorób skóry, błędnie uważaną za schorzenie dotykające wyłącznie nastolat- ków. Coraz częściej obserwuje się go u osób w wieku powyżej 20 lat [3,4]. Dumont-Wallon i Dreno sugerują, że trądzik późny kobiet jest przetrwałą formą trądziku młodzieńczego [4], co potwierdza również obserwacja, że u trzech czwartych naszych respondentek pierwsze zmiany trądzikowe pojawiły się przed 16 rokiem życia. $\mathrm{W}$ trądziku późnym zalecane jest odmienne podejście diagnostyczne i terapeutyczne $[1,2,5]$. Trądzik późny różni się od trądziku młodzieńczego między innymi tym, że występuje głównie w okolicy ust, brody, na linii żuchwy, czasami na ramionach, klatce piersiowej lub plecach $[2,4,6]$. Również wśród przebadanych przez nas Polek zmiany trądzikowe lokalizowały się najczęściej w obrębie brody. Podobnie jak we wcześniejszych badaniach [4,5,7], także u zdecydowanej większości naszych respondentek (84\%) dochodziło do nasilenia trądziku przed miesiączką.

Tabela 3. Wpływ zmian trądzikowych na codzienne zachowania kobiet $(\mathrm{N}=95)$

\begin{tabular}{l|c|c}
\multicolumn{1}{c|}{ Sytuacje, zachowania } & $\mathbf{n}$ & \% (95\% CI) \\
\hline $\begin{array}{l}\text { Sprawdzam swój wygląd w lustrze co najmniej kilka } \\
\text { razy dziennie }\end{array}$ & 42 & $44(34-54)$ \\
\hline $\begin{array}{l}\text { Idąc ulicą przeglądam się w szybach samochodów } \\
\text { sprawdzając, jak wyglądam }\end{array}$ & 30 & $32(22-41)$ \\
\hline $\begin{array}{l}\text { Myję twarz co najmniej kilka razy dziennie, aby mieć } \\
\text { kontrolę nad thustością skóry }\end{array}$ & 21 & $22(14-30)$ \\
\hline $\begin{array}{l}\text { Co najmniej kilka razy dziennie poprawiam makijaż, } \\
\text { nakładam puder, aby zmiany trądzikowe nie były } \\
\text { widoczne }\end{array}$ & 19 & $20(12-28)$ \\
\hline $\begin{array}{l}\text { Idąc ulicą mam wrażenie, że ciągle ktoś na mnie } \\
\text { patrzy }\end{array}$ & 11 & $12(5-18)$ \\
\hline $\begin{array}{l}\text { Wydaję dużo pieniędzy na kosmetyki do pielęgnacji } \\
\text { skóry trądzikowej }\end{array}$ & 10 & $11(4-17)$ \\
\hline $\begin{array}{l}\text { Myję twarz co najmniej kilka razy dziennie, gdyż } \\
\text { ciągle mam uczucie, że moja twarz jest brudna }\end{array}$ & 9 & $10(4-15)$ \\
\hline $\begin{array}{l}\text { Wydaję dużo pieniędzy na specjalistyczne zabiegi } \\
\text { kosmetyczne }\end{array}$ & 6 & $6(1-11)$ \\
\hline $\begin{array}{l}\text { Często zakrywam zmiany trądzikowe (noszę długie } \\
\text { włosy, noszę długą grzywkę, zakrywam twarz przy } \\
\text { pomocy chust, szali) }\end{array}$ & 5 & $5(1-10)$ \\
\hline $\begin{array}{l}\text { Będąc w grupie ludzi mam wrażenie, że ciągle ktoś } \\
\text { obgaduje/wyśmiewa wygląd mojej skóry }\end{array}$ & 5 & $5(1-10)$ \\
\hline $\begin{array}{l}\text { Wydaję dużo pieniędzy na leczenie mojego trądziku } \\
\text { konsultacje dermatologiczne, leki) }\end{array}$ & 5 & $5(1-10)$ \\
\hline $\begin{array}{l}\text { Znajomi/rodzina ciągle udzielają mi uwag na temat } \\
\text { mojej skóry }\end{array}$ & 3 & $3(0-7)$ \\
\hline $\begin{array}{l}\text { Podczas rozmowy z drugą osobą nigdy nie utrzymuję } \\
\text { kontaktu wzrokowego }\end{array}$ & 1 & $1(0-3)$ \\
\hline
\end{tabular}

Częstość występowania trądziku w zbadanej przez nas grupie młodych dorosłych Polek (chorobowość życiowa 74\%; chorobowość punktowa 55\%) jest zbliżona do wskaźników obserwowanych u saudyjskich kobiet powyżej 20 roku życia (51-55\%) i portugalskich studentów medycyny $(62 \%)$ [8,9]. Różnice w wynikach badań nad epidemiologią trądziku późnego w różnych grupach mogą wynikać z różnic kulturowych oraz geograficznych, ale także z różnic metodologicznych i definicji trądziku późnego. Wyniki naszego badania oparte są na własnej percepcji respondentów na temat obecności lub nieobecności trądziku, a zatem zależą od 
poziomu wiedzy i indywidualnych przekonań uczestniczek badania. Dobrą ilustracją znaczenia subiektywnego postrzegania problemów skórnych w badaniach ankietowych jest obserwacja $\mathrm{z}$ badań dorosłych mieszkańców wiejskiej gminy w województwie lubelskim, w których występowanie objawów trądziku kiedykolwiek w życiu zgłaszało zaledwie $4,8 \%$ badanych $(95 \% \mathrm{CI}=1,3-8,3 \%)$ [10]. Ta znacząco niższa częstość w porównaniu do wartości uzyskanych w niniejszej pracy zapewne bardziej wynika z obserwowanej w codziennym życiu skłonności mieszkańców wsi do bagatelizowania mniej uciążliwych chorób skóry, niż z faktycznych różnic międzypopulacyjnych. Z drugiej strony, bieżące wyniki oparte są na badaniach ankietowych studentów kierunków medycznych i kosmetologii, a respondentki wydają się bardziej wiarygodnym źródłem informacji.

Wyniki licznych badań sugerują, że trądzik związany jest ze znacznym spadkiem jakości życia, szczególnie u dorastającej młodzieży w okresie dojrzewania emocjonalnego [7,11-17]. Również u dojrzałych kobiet z trądzikiem późnym opisywano negatywny wpływ trądziku późnego na funkcjonowanie w społeczeństwie, a także skłonność chorych do depresji, niepewności, złości i obniżonej samooceny $[8,9,18]$. W tym zakresie nasze wyniki różnią się od wymienionych wcześniej, jako że wskazują one, że zmiany trądzikowe tylko w niewielkim stopniu wpływają na jakość życia dorosłych Polek. Do wniosków podobnych jak w niniejszej pracy doszli wcześniej w swoich badaniach tylko Poli i wsp. [7]. Rozbieżność wyników uzyskanych w poszczególnych badaniach może wynikać z różnic metodologicznych, odmiennego nasilenia choroby w badanych populacjach, czy też różnic kulturowych, w tym niejednakowych oczekiwań co do wyglądu zewnętrznego w badanych społecznościach [19]. Jakość życia jest pojęciem subiektywnym, a jej poziom może zależeć od kontekstu społecznego, a także indywidualnych umiejętności radzenia sobie ze stresem i zdolności do akceptacji swojego wyglądu [20].

\section{Wnioski}

Trądzik późny dotyczy ponad połowy młodych dorosłych Polek i zazwyczaj jest kontynuacją trądziku młodzieńczego. Choroba ta obniża poczucie własnej atrakcyjności u dotkniętych nią kobiet i wpływa na ich codzienne zachowania, jednak w większości przypadków nie powoduje znacznego obniżenia jakości życia i nie stanowi istotnej przeszkody w codziennym funkcjonowaniu oraz kontaktach międzyludzkich.

\section{Piśmiennictwo}

1. Preneau S, Dreno B: Female acne - a different subtype of teenager acne? J Eur Acad Dermatol Venereol 2012; 26(3):277-82.

2. Williams C, Layton AM: Persistent acne in women: implications for the patient and for therapy. Am J Clin Dermatol 2006; 7(5):281-90.

3. Collier CN, Harper JC, Cafardi JA, Cantrell WC, Wang W, Foster KW, Elewski BE: The prevalence of acne in adults 20 years and older. J Am Acad Dermatol 2008; 58(1):56-9.

4. Dumont-Wallon G, Dreno B: Specificity of acne in women older than 25 years. Presse Med 2008; 37(4 Pt 1):585-91.

5. Rivera R, Guerra A: Management of acne in women over 25 years of age. Actas Dermosifiliogr 2009; 100(1): 33-7.

6. Knaggs HE, Wood EJ, Rizer RL, Mills OH: Postadolescent acne. Int J Cosmet Sci 2004; 26(3):129-38.

7. Poli F, Dreno B, Verschoore M: An epidemiological study of acne in female adults: results of a survey conducted in France. J Eur Acad Dermatol Venereol 2001; 15(6): 541-45.

8. Al-Robaee AA: Prevalence, knowledge, beliefs and psychosocial impact of acne in University students in Central Saudi Arabia. Saudi Med J 2005; 26(12): 1958-61.

9. Goncalves G, Amado JM, Matos ME, Massa A: The prevalence of acne among a group of Portuguese medical students. J Eur Acad Dermatol Venereol 2012; 26(4): 514-7.

10. Śpiewak R: Częstość występowania chorób skóry w losowej grupie dorosłych Polaków. Estetol Med Kosmetol 2012; 2(2):50-3.

11. Walker N, Lewis-Jones MS: Quality of life and acne in Scottish adolescent schoolchildren: use of the Children's Dermatology Life Quality Index (CDLQI) and the Cardiff Acne Disability Index (CADI). J Eur Acad Dermatol Venereol 2006; 20(1):45-50.

12. Rolka H, Lewko J, Kuprianowicz M, Łukaszuk C, Krajewska- Kułak E, Baranowska A, Jankowiak B, Niczyporuk W, Niczyporuk M: Wpływ zmian trądzikowych na wybrane parametry jakości życia. Dermatologia Kliniczna 2008; 10(1):15-9

13. Hanisah A, Omar K, Shah SA: Prevalence of acne and its impact on the quality of life in school-aged adolescents in Malaysia. J Prim Health Care 2009; 1(1): 20-5.

14. Zahra Ghodsi S, Orawa H, Zouboulis CC: Prevalence, severity, and severity risk factors of acne in high school pupils: a community-based study. J Invest Dermatol 2009; 129(9):2136-41.

15. Kurtalic N, Hadzigrahic N, Tahirovic H, Sijercic N: Quality of life of adolescents with acne vulgaris. Acta Med Croatica 2010; 64(4):247-51.

16. Bowe WP, Doyle AK, Crerand CE, Margolis DJ, Shalita AR: Body image disturbance in patients with acne vulgaris. J Clin Aesthet Dermatol 2011; 4(7):35-41.

17. Safizadeh H, Shamsi-Meymandy S, Naeimi A: Quality of life in Iranian patients with acne. Dermatol Res Pract 2011; 2012: 571516.

18. Pruthi GK, Babu N: Physical and psychosocial impact of acne in adult females. Indian J Dermatol 2012; 57(1): 26-9. 
19. Kokandi A: Evaluation of acne quality of life and clinical severity in acne female adults. Dermatol Res Pract 2010; 2010.pii: 410809.

20. Bernheim JL: How to get serious answers to the serious question: „How have you been?”: subjective quality of life (QOL) as an individual experiential emergent construct. Bioethics 1999;13(3-4):272-87.

\section{Finansowanie i konflikt interesów}

Dane przedstawione w niniejszej pracy zostały zebrane przez Paulinę Szczurek w ramach pracy magisterskiej „Częstość występowania trądziku późnego oraz jego wpływ na jakość życia studentów Wydziału Farmaceutycznego Uniwersytetu Jagiellońskiego" (promotor: Radosław Śpiewak, opiekun: Grażyna Kamińska-Winciorek) obronionej 5 lipca 2012 roku na Wydziale Farmaceutycznym UJ. Autorzy deklarują niewystępowanie konfliktu interesów w odniesieniu do treści zawartych $\mathrm{w}$ niniejszej pracy.

\section{Adres do korespondencji}

Radosław Śpiewak

Zakład Dermatologii Doświadczalnej i Kosmetologii

Wydział Farmaceutyczny UJ

ul. Medyczna 9, 30-688 Kraków

Tel.: 1262058 30, Fax: 126205645

E-mail: spiewak.eu@gmail.com

Data złożenia: 29.06.2012

Data akceptacji: 19.07.2012

Data aktualizacji: 30.11 .2012

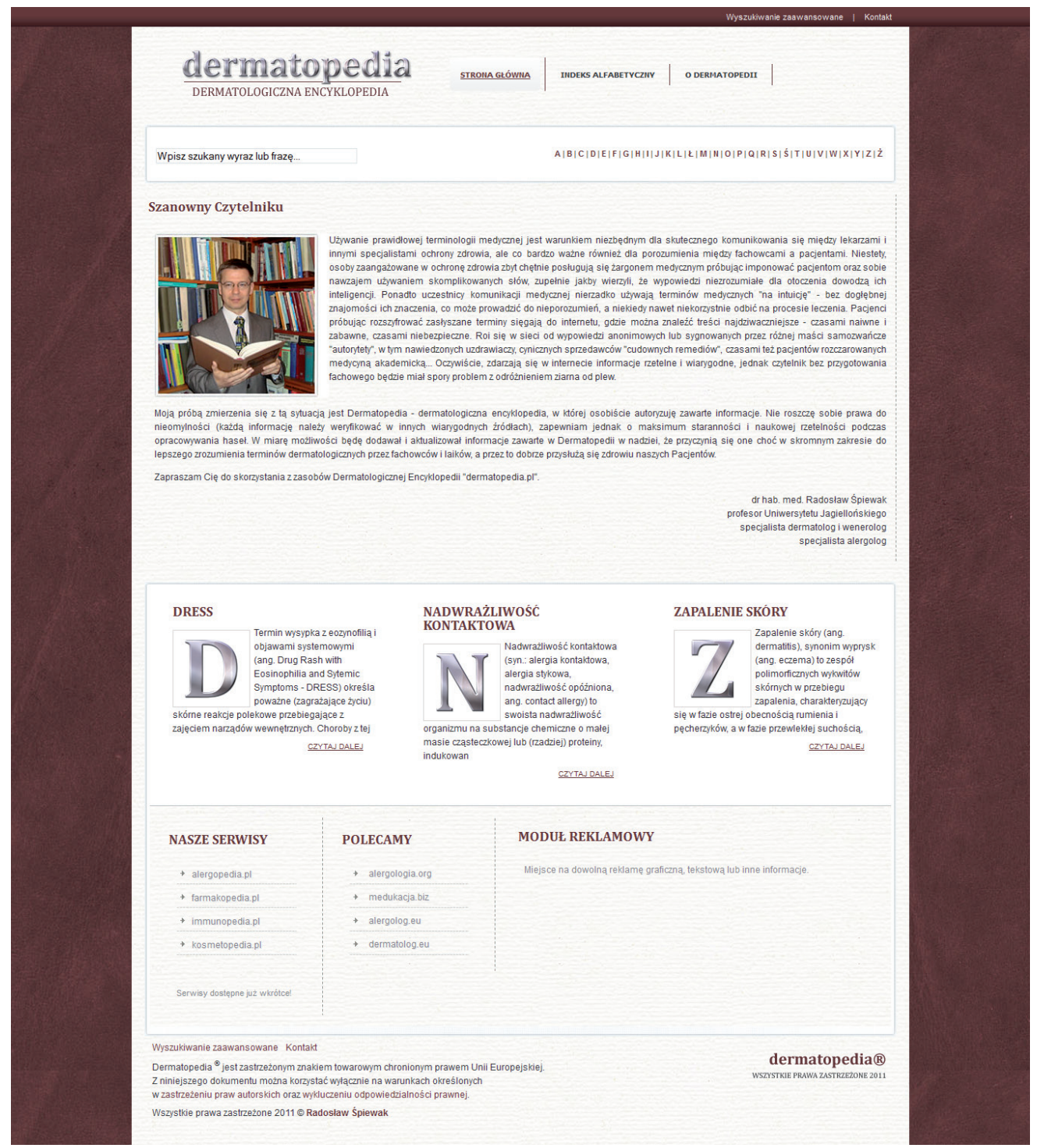

